\title{
Author Correction: Sister chromatid resolution is an intrinsic part of chromosome organization in prophase
}

Kota Nagasaka, M. Julius Hossain, M. Julia Roberti, Jan Ellenberg and Toru Hirota

Correction to: Nature Cell Biology https://doi.org/10.1038/ncb3353, published online 2 May 2016.

In the version of this Letter originally published, the authors omitted a citation of an early study demonstrating topoisomerase-II-dependent sister chromatid resolution. This reference has now been added to the reference list as reference number 28 , and the relevant text has been amended as follows to include its citation: 'Resolution must reflect the removal of sister-sister contacts, and we show here that Topo-II $\alpha$-mediated release of DNA catenation plays a major role (Fig. 4), in agreement with previous findings ${ }^{28}$, whereas, surprisingly, cohesin dissociation is not strictly required (Fig. 3).' Subsequent references have been renumbered. All online versions of the Letter have been updated to reflect this change.

28. Giménez-Abián, J. F., Clarke, D. J., Mullinger, A. M., Downes, C. S. \& Johnson, R. T. A postprophase topoisomerase II-dependent chromatid core separation step in the formation of metaphase chromosomes. J. Cell Biol. 131, 7-17 (1995).

Published online: 12 February 2018

https://doi.org/10.1038/s41556-018-0044-0

\section{Author Correction: Basolateral protrusion and apical contraction cooperatively drive Drosophila germ-band extension}

Zijun Sun, Christopher Amourda, Murat Shagirov, Yusuke Hara, Timothy E. Saunders and Yusuke Toyama

Correction to: Nature Cell Biology https://doi.org/10.1038/ncb3497, published online 27 March 2017.

In the version of this Article originally published, the authors cited the wrong articles for reference numbers 18, 30 and 31 ; the correct ones are listed below. Furthermore, four additional references have been inserted at numbers 37, 38, 39 and 40 as in the list below, and the original references 37-40 have been renumbered. These corrections have been made in the online versions of the Article.

18. Shih, J. \& Keller, R. Cell motility driving mediolateral intercalation in explants of Xenopus laevis. Development 116, 901-914 (1992).

30. Shih, J. \& Keller, R. Patterns of cell motility in the organizer and dorsal mesoderm of Xenopus laevis. Development 116, 915-930 (1992).

31. Jessen, J. R. et al. Zebrafish trilobite identifies new roles for Strabismus in gastrulation and neuronal movements. Nat. Cell Biol. 4, 610-615 (2002).

37. Shindo, A. \& Wallingford, J. B. PCP and septins compartmentalize cortical actomyosin to direct collective cell movement. Science 343, 649-652 (2014).

38. Williams, M., Yen, W., Lu, X. \& Sutherland, A. Distinct apical and basolateral mechanisms drive planar cell polarity-dependent convergent extension of the mouse neural plate. Dev. Cell 29, 34-46 (2014).

39. Walck-Shannon, E. \& Hardin, J. Cell Intercalation from top to bottom. Nat. Rev. Mol. Cell Biol. 15, 34-48 (2014).

40. Shindo, A. Models of convergent extension during morphogenesis. WIREs Dev. Biol. 7, e293 (2018).

Published online: 5 March 2018

https://doi.org/10.1038/s41556-018-0069-4 